\title{
Efeitos de treinos sucessivo e concomitante sobre a recombinação de repertórios de cavar e escalar em Rattus norvegicus
}

\section{Effects of successive and concomitant training upon the interconnection of dig and climbing repertoires in Rattus norvegicus \\ Efectos de entrenamientos sucesivo y simultáneo sobre la interconexión de repertorios de escavar y escalar por Rattus norvegicus}

\author{
Hernando Borges Neves Filho', Rodrigo Harder Ferro Dicezare², Alceu Martins Filho ${ }^{3}$, Miriam Garcia-Mijares ${ }^{4}$
}

\footnotetext{
[1] Pontifícia Universidade Católica de Goiás [2-4] Universidade de São Paulo | Título abreviado: Recombinação de repertórios em ratos | Endereço para correspondência: Pontifícia Universidade Católica de Goiás, ÁREA IV, Programa de Pós-graduação Strictu Senso em Psicologia, Av. Universitária, N. 1069, Setor Leste Universitário, Goiânia - GO, CEP. 74605-010 I Email: hernandonevesfilho@gmail.com I DOI: 10.18761/pac.2016.013
}

\begin{abstract}
Resumo: A recombinação de repertórios é um processo comportamental relacionado a resolução de problemas e origem de comportamentos novos. O presente estudo teve por objetivo testar o efeito de treinos concomitante e sucessivo sobre a recombinação de dois repertórios: (a) cavar, e; (b) escalar, em ratos (Rattus norvegicus). Seis ratos foram alocados dois a dois em três condições de treino. Em uma condição, os repertórios foram treinados em duas sessões diárias, uma de cada repertório (condição concomitante, $n=2$ ). Na segunda condição, foram realizadas uma sessão por dia, e primeiro foi treinado o repertório de cavar, e depois de encerrado o treino de cavar, foi treinado o repertório de escalar (condição sucessiva, $n=2$ ). Em uma terceira condição $(n=2)$, foi feito o treino sucessivo idêntico a segunda condição, com a adição de sessões de retomada do primeiro repertório treinado, antes do teste. Para testar a recombinação, os animais foram expostos a uma situação problema cuja solução exigia que cavassem e encontrassem uma fresta que dava acesso a escadas que chegavam em uma plataforma com comida, uma sequência de respostas nunca diretamente treinada. Todos os sujeitos, das três condições, resolveram a tarefa final, porém com topografias de resolução do problema distintas. Os sujeitos da condição concomitante resolveram o problema em menor tempo, em comparação com os demais sujeitos. Com base nos dados, são avaliados os efeitos de variáveis de treino sobre a recombinação de repertórios e os critérios utilizados para avaliar diferentes topografias de solução de um mesmo problema.
\end{abstract}

Palavras-chave: resolução de problemas, comportamento novo, criatividade, insight, ratos 


\begin{abstract}
The interconnection of repertoires is a behavioral process related to problem solving and the origins of new behavior. The present study observed the effects of concomitant and successive training of (a) dig, and; (b) climb, upon the interconnection of repertoires in rats (Rattus norvegicus). Pairs of rats received different trainings before testing. In the first condition, a pair of rats received two sessions per day, one of dig and the other of climbing (concomitant condition, $\mathrm{n}=2$ ). A second pair of subjects first learned to dig, and then to climb (successive condition, $\mathrm{n}=2$ ). In a third condition $(\mathrm{n}=2)$, rats learned the two repertoires in a successive manner, and had retraining sessions of the first trained repertoire before testing. To test the interconnection, rats were exposed to a new task that required a sequence of behaviors never trained: the animals had to dig and find a tunnel, which leaded to a flight of stairs containing food at its end. All subjects solved the final task, but with different topographies of problem solving. Rats of the concomitant condition solved the problem in less time than rats in other conditions. A discussion is offered regarding the general effects of different training variables upon the interconnection of repertoires and the criteria used to evaluate different problem solving topographies.
\end{abstract}

Keywords: problem solving, new behavior, creativity, insight, rats

Resumen: La interconexión de repertorios es un proceso de comportamiento implicado en la solución de problemas y en el origen de nuevos comportamientos. Este estudio tuvo como objetivo evaluar el efecto de diferentes regímenes de entrenamiento sobre la interconexión de dos repertorios: (a) excavar y (b) subir. Pares de ratas (Rattus norvegicus) fueron designadas a tres condiciones experimentales. En la primera condición, los repertorios fueron entrenados en sesiones intercaladas en el mismo día (entrenamiento concomitante, $n=2$ ); en la segunda condición, fue primero entrenado el repertorio de excavar y después el de subir (entrenamiento sucesivo, $n=2)$; el entrenamiento en la tercera condición $(n=2)$ fue semejante al del segundo, pero antes del teste fue realizado el entrenamiento concomitante de los dos repertorios. Para probar la interconexión, las ratas fueron expuestas a una nueva tarea: los animales tuvieron que cavar y encontrar un túnel, que lideró a un tramo de escaleras que contienen los alimentos en su extremo. Todas las ratas resolvieron el problema, pero mostraron diferentes topografías de resolución. Las ratas de la condición concomitante resolvieron el problema en menos tiempo que las ratas en otras condiciones. Una discusión se ofrece en relación con los efectos generales de las diferentes variables de entrenamiento sobre la interconexión de los repertorios y los criterios utilizados para evaluar las diferentes topografías de resolución de problemas.

Palabras-clave: solución de problemas, comportamiento nuevo, creatividad, insight, ratas 
No começo do século XX, Wolfgang Köhler (1887-1967), um dos fundadores da Psicologia da Gestalt, publicou uma série de estudos sobre inteligência animal, utilizando chimpanzés (Pan troglodytes) como sujeitos. No seu trabalho intitulado Intelligenzenprüfungen an Menschenaffe, traduzido para o inglês como The Mentality of Apes (1917/1948), Köhler observou um tipo de resolução de problemas súbita, direcionada e contínua, que chamou de "insight" (Köhler, 1917/1948, p. 174). Este "insight" seria, segundo o autor, um tipo de desempenho distinto de instâncias de tentativa-e-erro, como as encontradas por Thorndike (1911) com gatos em caixa problema (para uma revisão de como estas duas visões foram confrontadas na época, cf. Hartmann, 1933; Thorpe, 1963; Holt, 2008; Ruiz \& Sanchéz, 2014). Um dos desempenhos clássicos de "insight" relatados por Köhler foi o de um chimpanzé chamado Sultão, que possuía ao seu alcance um par de ferramentas encaixáveis e uma banana fora do alcance de seus braços (mesmo com o uso das partes desencaixadas da ferramenta) (Köhler, 1917/1948, p. 127). Nesta situação problema, Sultão de início tentou alcançar a banana com seus braços e com as partes individuais da ferramenta, sem obter sucesso. Após mais de uma hora de sessão, na qual Sultão manipulou o par de varetas e emitiu diversos outros comportamentos, Sultão se aproximou das ferramentas e uniu o par, formando uma ferramenta longa que prontamente utilizou para alcançar o alimento com sucesso. Desempenhos similares foram observados em tarefas de empilhamento de caixas, que davam acesso a um alimento (Köhler, 1917/1948). Köhler atribuiu os lampejos e soluções súbitas de Sultão ao produto de uma "reestruturação do campo perceptual do sujeito", em outras palavras, a uma nova forma de perceber a relação entre eventos, e ressaltou que isso não seria um "fenômeno mental" (Köhler, 1917/1948, p. 267; Köhler, 1959, p. 728) ${ }^{1}$. Köhler, entretanto, reconheceu uma limitação grave de seus estudos: o fato de que não sabia a história completa de seus sujeitos, mas concluiu acertadamente que animais em situações problemas podem resolvê-las de diversas formas, sendo elas súbitas ou não (Köhler, 1917/1948, p. 265).

Partindo dos estudos de Köhler, uma série de experimentos investigaram quais espécies de ani- mais solucionavam problemas subitamente e qual o papel do treino sobre o "insight" (para uma revisão destes trabalhos, cf. Shettleworth, 2012; Neves Filho, 2015). Dos trabalhos sobre o efeito do treino sobre a resolução súbita de um problema, um experimento bastante conhecido é o de Epstein, Kirshnit, Lanza e Rubin (1984), que reproduziu o desempenho súbito de Sultão, com pombos (Columba livia). A tarefa, posteriormente denominada de teste de deslocamento de caixa (Cook \& Fowler, 2014), consistiu em empurrar uma caixa em direção a uma banana de plástico afixada no teto da câmara experimental, subir na caixa e bicar a banana. Os repertórios pré-requisito para a tarefa foram treinados independentemente (de forma não encadeada). Os repertórios foram: (a) empurrar a caixa na direção de um alvo localizado na lateral da câmara experimental e (b) subir em uma caixa e bicar uma banana de plástico fixa no teto da câmara experimental. Depois os animais foram colocados na situação de teste: caixa afastada da banana. No início da sessão de teste, os pombos emitiram respostas direcionadas a caixa e a banana, como esticar o pescoço em direção a banana e subir na caixa. Passado este momento inicial, os animais começaram a empurrar a caixa em direção à banana, parando de empurrar a caixa assim que esta estava próxima da banana, imediatamente subindo na caixa e bicando a banana. Esse desempenho foi denominado por Epstein et al. (1984) de "recombinação espontânea de repertórios previamente adquiridos".

Adicionalmente, Epstein et al. (1984) observaram que pombos que não aprenderam um dos repertórios ou que aprenderam partes desses repertórios (como empurrar de forma não direcionada) não resolveram o problema, ou resolveram ao acaso, sem a mesma topografia de solução fluida apresentada pelos sujeitos que passaram pelo treino completo dos repertórios pré-requisito.

A recombinação de repertórios, como descrita por Epstein et al. (1984) é considerada como uma descrição comportamental da resolução súbita de problemas, tradicionalmente conhecida como “insight" (Neves Filho \& Carvalho Neto, 2013; Carvalho Neto, Barbosa, Neves Filho, Delage \& Borges, 2016). Para que ocorra a resolução súbita de um problema é necessário que pré-requisitos desta tarefa tenham sido aprendidos, mesmo que 
de forma independente. Após isto, dado o controle de estímulos adequado (a situação problema), estes repertórios aprendidos são recombinados em uma sequência nova. Diversos outros estudos de recombinação de repertórios com pombos foram realizados desde então, todos utilizando variações do teste de deslocamento de caixa, como a recombinação de três (Epstein, 1985; Luciano, 1991) e quatro repertórios (Epstein, 1987). Em um estudo recente, Cook e Fowler (2014) replicaram o trabalho original com dois repertórios (Epstein et al., 1984) e adicionaram testes de entendimento de causalidade ao final da tarefa. A recombinação de repertórios também foi observada em corvos da Nova Caledônia (Taylor, Elliffe, Hunt \& Gray, 2010; Neves Filho, 2015), macacos prego (Delage, 2010; Delage \& Galvão, 2011; Neves Filho, Carvalho Neto, Barros \& Costa, 2014; Neves Filho, Carvalho Neto, Tayteulbaum, Malheiros \& Knaus, 2016) e humanos (Sturz, Bodily \& Katz, 2009).

No Brasil, uma série de dissertações de mestrado (Delage, 2006; Tobias, 2006; Ferreira, 2008; Leonardi, 2012) tiveram por objetivo reproduzir a recombinação de repertórios no teste de deslocamento de caixa com ratos albinos (Rattus norvegicus) como sujeitos. Em nenhum destes trabalhos foi observada a recombinação fluída dos repertórios nos moldes descritos nos trabalhos originais com pombos (Leonardi, Andery \& Rossger, 2011) e somente um rato no trabalho de Tobias (2006) e outro no de Ferreira (2008) resolveram o teste de deslocamento de caixa, depois de extenso treino das habilidades pré-requisito e repetidas exposições à situação problema.

O teste de deslocamento de caixa é um problema predominantemente visual (empurrar caixas em direção a uma luz ou alvo, subir em uma caixa e puxar uma argola acima da cabeça do sujeito). Rattus norvegicus têm baixa acuidade visual (cf. Slotnick \& Schellinck, 2002). Portanto, a tarefa de deslocamento de caixa pode ser menos apropriada para essa espécie do que tarefas que estimulem outros sistemas sensoriais, como olfato e tato (Iversen, 2008).

Certamente refinamentos procedimentais podem ser feitos, especialmente no que tange o treino de repertórios pré-requisito, para que ratos resolvam a tarefa de deslocamento de caixa; contudo, um procedimento alternativo, que produz o mesmo fenômeno de resolução súbita, foi apresentado por Maier (1931, 1937). Um dos procedimentos de Maier (1931), com ratos, consistiu em expor os sujeitos a uma mesa, que possuía uma escada que dava acesso ao solo. Um dos cantos dessa mesa era fechado por uma grade, portanto, inacessível aos sujeitos. Na primeira etapa do experimento, os animais tinham livre acesso à mesa e a escada, e aprenderam a subir e descer a escada (experiência 1). Em uma segunda etapa, outra mesa foi colocada na sala, e uma ponte ligava-a ao local inacessível da primeira mesa, e três escadas distintas conectavam esta nova mesa ao solo. Nesta etapa os animais aprenderam, por exploração, a subir do solo até a nova mesa, e cruzar a ponte da nova mesa até a área inacessível da primeira mesa (experiência 2). Nenhum treino operante explícito foi realizado no estabelecimento desses repertórios. A situação de teste consistiu em colocar os animais na primeira mesa, conectada a segunda e apresentar alimento na área inacessível da primeira mesa. Para solucionar o problema, os animais deveriam recombinar a experiência 1 , descer da primeira mesa ao solo, com a experiência 2; do solo, subir até a segunda mesa, e cruzar a ponte até o local onde havia alimento na primeira mesa. Todos os animais resolveram o problema, inicialmente tentando alcançar o alimento através da grade e, posteriormente, iniciando a sequência de respostas que levava à solução. Em sujeitos controles, o autor treinou as experiências $1 \mathrm{e}$ 2 em locais diferentes do local do teste e, neste caso, os sujeitos não resolveram a tarefa final. Um outro grupo de animais passou por somente uma das experiências (1 ou 2) e também não resolveram a tarefa. Maier (1937) empregou o termo "reasoning" para descrever essa resolução súbita de problemas que se daria a partir da integração espontânea de experiências aprendidas isoladamente.

Com base no procedimento de Maier (1931, 1937), Neves Filho, Stella, Dicezare e GarciaMijares (2016) desenvolveram um novo problema para ratos, envolvendo repertórios de cavar e escalar. Neves Filho et al. treinaram ratos (Rattus norvegicus) a: (a) cavar na maravalha, e; (b) escalar dois lances de escada. Os dois repertórios tinham como consequência uma porção de alimento. No teste final, os animais foram colocados em uma câmara 
experimental que possuía uma placa de acrílico que a separava ao meio. A placa de acrílico possuía uma fresta na sua porção inferior. Essa fresta e todo o chão da câmara estavam completamente cobertos por maravalha. De um lado havia dois lances de escada que davam acesso a uma porção de alimento. $\mathrm{O}$ animal iniciava a sessão do outro lado da câmara, que permitia acesso visual ao recipiente com alimento, mas nenhum meio de alcançá-lo. Para resolver o problema, o animal deveria cavar na maravalha, encontrar a fresta coberta pela maravalha, atravessar para o outro lado da câmara experimental e subir os dois lances de escada para acessar o patamar contendo alimento. Primeiramente, todos os sujeitos passaram por uma sessão de pré-teste antes do treino dos repertórios, para averiguar se os animais eram capazes de solucionar a tarefa apenas por exploração e nenhum dos animais resolveu a tarefa nessa etapa. Os ratos que passaram pelo treino das duas habilidades $(n=2)$ resolveram a tarefa em alguns segundos (17 s e $33 \mathrm{~s}$ ), com a mesma topografia de solução fluída dos pombos de Epstein et al. (1984). Os ratos que receberam o treino de somente uma das habilidades $(\mathrm{n}=4)$, não resolveram o problema. Neves Filho et al. realizaram um treino adicional, pós-teste, com os ratos que aprenderam somente um dos repertórios e não resolveram a tarefa. Ratos que aprenderam somente a cavar e falharam no teste aprenderam a escalar e foram submetidos novamente ao teste, e ratos que aprenderam somente a escalar e falharam no teste receberam um treino de cavar e foram novamente testados. O treino pós-teste dado a estes animais foi breve, bastando seis respostas corretas consecutivas do repertório treinado para encerrar o treino (em comparação, os repertórios estabelecidos antes do primeiro teste utilizaram um critério de aprendizagem de vinte respostas corretas em quatro sessões consecutivas). Após este breve treino pós-teste, somente um dos quatro animais resolveu a tarefa, porém de forma não fluída e em um tempo maior (2 min 36 s), se comparado com os animais que receberam o treino dos dois repertórios antes do teste.

Os resultados de Neves Filho et al. (2015) indicaram que diferentes maneiras de treinar os repertórios pré-requisito podem produzir diferentes topografias de resolução de problema na tarefa de cavar e escalar. No caso, todos os ratos que apren- deram os dois repertórios pré-requisito antes do teste resolveram o problema de forma súbita, enquanto que animais que aprenderam os mesmos repertórios, um antes e outro depois de um primeiro teste, não resolveram a tarefa, ou resolveram ocasionalmente. A mesma dificuldade na recombinação de repertórios foi também observada quando estas variáveis foram manipuladas com pombos no teste de deslocamento de caixa (Neves Filho, 2015). Manipulações de variáveis de treino em uma tarefa de encaixar ferramentas e usar ferramentas para alcançar alimento com macacos-prego (Sapajus spp.), também alteraram a topografia de resolução do problema, ou impediram a recombinação (Neves Filho et al. 2014; Neves Filho et al. 2016). Um treino desbalanceado (maior quantidade de treino de alcançar alimentos em comparação com o treino de juntar ferramentas) produziu a típica topografia de "insight" nesta tarefa com macacos-prego, ao passo que um treino balanceado (mesma quantidade de treino dos dois repertórios) produziu uma típica topografia de resolução de tentativa-e-erro (Neves Filho et al. 2016). Por outro lado, Corvos da Nova Caledônia de vida livre, demonstraram a recombinação de repertórios, mesmo quando os repertórios foram treinados em contextos distintos, com diferentes quantidades de treino e diferentes tipos de reforçador para o treino de cada repertório (Taylor, Elliffe, Hunt \& Gray, 2010; Neves Filho, 2015).

Partindo dos efeitos particulares sobre a recombinação de repertórios que diferentes tipos de treino produzem, o presente trabalho teve como objetivo observar os efeitos de um treino concomitante (dois repertórios treinados em sessões intercaladas antes do teste) em comparação com um treino sucessivo (primeiro é ensinado um repertório e depois o outro, antes do teste) em ratos na tarefa de cavar e escalar.

Os dados de Neves Filho et al. (2015) indicaram que um treino concomitante produz a recombinação na tarefa de cavar e escalar em ratos. Os resultados dos animais que receberam treino sucessivo (um repertório treinado antes do primeiro teste, e outro após este teste) foram inconclusivos uma vez que o critério do treino do segundo repertório foi menor do que o usado no treino concomitante. Desta forma, não há como saber se a ordem ou sequência do treino das habilidades pré-requisito foi 
a variável responsável pela interferência observada na recombinação no segundo teste. Assim, o presente trabalho isolou estas variáveis, treinando seis ratos em três diferentes condições experimentais. Dois ratos foram treinados em um regime de treino concomitante dos dois repertórios, idêntico ao que resultou na resolução súbita em Neves Filho et al. Outros dois ratos foram treinados em um regime sucessivo, similar ao que não produziu a resolução no estudo de Neves Filho et al., e em uma terceira condição, dois outros ratos foram treinados em um regime sucessivo com sessões de retomada do primeiro e do segundo repertórios antes do teste. Com base nos dados obtidos nos experimentos anteriores que manipularam variáveis de treino, era esperado que: (1) o treino concomitante produzisse a recombinação, (2) que o treino sucessivo não resultasse na recombinação dos repertórios treinados e que (3) a terceira condição, de treino sucessivo com retomada produzisse a solução do problema, mas sem a topografia típica de "insight", como observado em pombos que receberam um treino sucessivo com retomada dos repertórios antes do teste de deslocamento de caixa (Neves Filho, 2015).

\section{Método}

\section{Sujeitos}

Seis ratos albinos (Rattus norvegicus), machos, da cepa Wistar, sem experiência em tarefas de cavar e subir escadas, pesando entre 390 e 420 gramas. Todos os seis ratos viviam no biotério do Instituto de Psicologia da Universidade de São Paulo, com controle de temperatura ambiente $\left(22-24^{\circ} \mathrm{C}\right)$ e ciclo claro-escuro $(12 \mathrm{~h}-12 \mathrm{~h})$ que foi controlado por uma câmara com acionamento e desligamento automático do período de luz. Os animais viviam em pares, em isoladores ALESCO $^{\infty}$ com piso forrado por maravalha (até aproximadamente $5 \mathrm{~cm}$ ). Os animais passaram por um regime de privação alimentar durante a realização do experimento, no qual tiveram à disposição $15 \mathrm{~g}$ diárias de ração por rato, complementado pela apresentação de cereais açucarados durante as sessões experimentais. Os seis ratos foram mantidos entre 80 e $85 \%$ do seu peso ad-libitum durante o período de realização do experimento. Todos os procedimentos foram previamente aprovados pela Comissão de Ética no Uso de Animais (CEUA No 2783170216) da Universidade de São Paulo.

\section{Equipamento}

Uma caixa padrão ALESCO $^{\circledast}(48 \times 37 \times 25 \mathrm{~cm})$ de policarbonato transparente, similar a caixa na qual os animais residiam no biotério, foi utilizada no treino de cavar. A caixa foi preenchida com maravalha até $20 \mathrm{~cm}$ de altura desde sua base. A caixa não possuía teto.

Uma caixa com piso de epoxi e paredes e teto de grades de aço (fabricada pela empresa Monaco) foi utilizada para o treino de escalar. A caixa, de dimensões $48 \times 37 \times 40 \mathrm{~cm}$, possuía no seu interior dois lances de escada, também feitas de aço, como as paredes. As escadas conectavam o piso a um segundo andar.

A caixa de teste $(48 \times 37 \times 65 \mathrm{~cm})$ foi uma junção das caixas de treino. A parte inferior era a caixa de cavar, e a parte superior eram as paredes e teto de aço, da caixa do treino de escalar, contendo as escadas. A caixa de teste possuía uma placa de acrílico transparente dividindo-a verticalmente em duas metades (18,5 cm cada metade). No canto inferior direito da placa de acrílico havia uma fresta $(10 \mathrm{~cm} \times 10 \mathrm{~cm})$. Durante o teste, o piso da caixa foi coberto de maravalha (até a altura de $20 \mathrm{~cm}$ ). A maravalha cobria totalmente a fresta na porção inferior da placa de acrílico (Figura 1). Também foram utilizadas, durante o treino e teste, recipientes (tampas de refrigerante) nos quais foram disponibilizados pedaços de cereais açucarados (Kellogs Froot Loops ${ }^{\mathrm{Tx}}$ ).

$\mathrm{Na}$ coleta de dados, foram utilizadas folhas de registro de ocorrência e tempo de respostas discretas (cavar e escalar), e as funções de cronômetro e filmadora de um smartphone Samsung Galaxy GTI9192.

\section{Procedimento geral}

Antes do treino, todos os animais passaram por uma sessão de pré-teste. A sessão de pré-teste foi idêntica à sessão de teste. Na caixa de pré-teste e teste (Figura 1), de um lado, separado pela placa de acrílico, estavam as escadas que davam acesso ao recipiente contendo um pedaço de cereal açuca- 


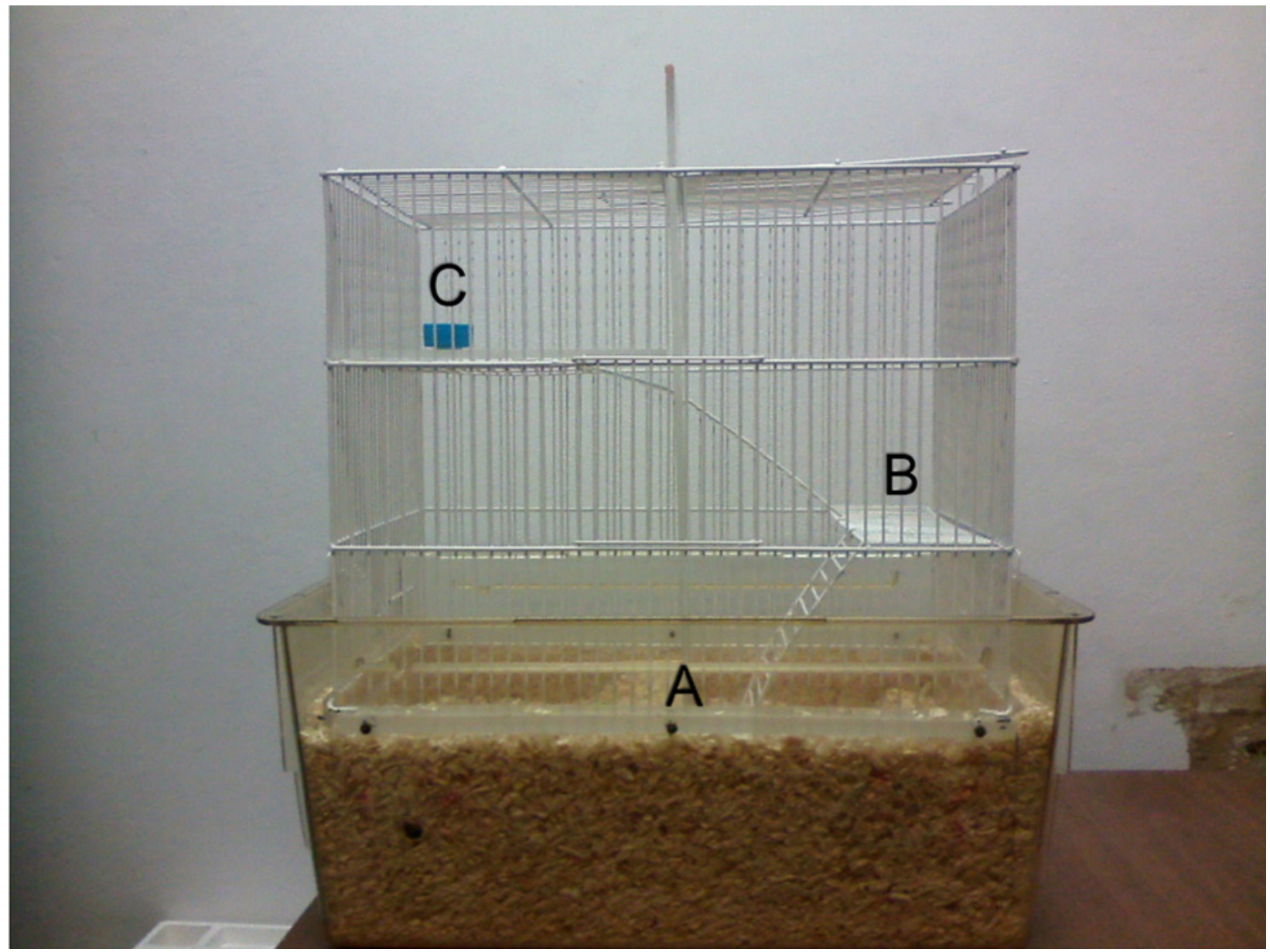

Figura 1. Caixa de teste. $\mathrm{O}$ item $(\mathrm{A})$ indica a placa de acrílico translúcido que dividia a caixa ao meio. No teste, o animal começou a sessão no lado que não possuí escadas (lado esquerdo na foto). A placa de acrílico se estendia do topo da caixa até o seu piso, sendo que próximo ao piso, totalmente coberto pela maravalha, havia uma fresta na placa de acrílico que permitia o acesso ao outro lado da caixa. (B) indica as duas escadas, que davam acesso a (C), o recipiente contendo o cereal açucarado.

rado. Os animais iniciavam a sessão do outro lado da caixa e para alcançar a escada precisavam cavar na maravalha, encontrar o buraco na barreira de acrílico (que estava totalmente coberto por maravalha), atravessar para o outro lado e então subir as escadas.

Após o pré-teste, não havendo a solução do problema por exploração, iniciou-se o treino dos dois repertórios pré-requisito: (1) cavar na maravalha e (2) escalar dois lances de escadas. Cada sessão foi constituída de 20 min de exposição ao equipamento experimental ou a obtenção de 15 cereais açucarados.

O repertório de cavar foi ensinado em três etapas de modelagem; na primeira, o recipiente contendo um pedaço do cereal foi colocado sobre a maravalha em diferentes posições a cada tentativa.
Na segunda etapa, a tampa contendo o cereal foi coberta por maravalha (de 2 a $5 \mathrm{~cm}$ ), e na terceira etapa a tampa contendo cereal foi colocada no fundo da caixa, totalmente coberta por maravalha. Até quatro recipientes contendo cereais foram escondidos simultaneamente no fundo da caixa na terceira etapa, sempre em diferentes pontos, de modo que o comportamento de cavar pudesse ser direcionado, similar ao treino de empurrar a caixa realizado por Epstein et al. (1984). No momento em que o rato obtivesse 15 cereais açucarados a sessão era encerrada, não importando o tempo transcorrido.

O repertório de escalar dois lances de escadas foi modelado a partir das seguintes etapas: subir o primeiro patamar e subir os dois patamares. $\mathrm{O}$ reforçador (cereal açucarado) foi disponibilizado dentro do mesmo recipiente utilizado no treino de 
cavar. Após o obter o alimento, o experimentador aguardava o animal retornar ao piso da caixa, para assim colocar outro pedaço de alimento no recipiente, de modo que não fosse necessário retirar o animal da caixa a cada tentativa. As sessões de treino foram encerradas após o animal obter 15 cereais açucarados ou após 20 min de sessão.

Nas sessões de treino, todas as respostas foram registradas em folhas de registro, e o tempo foi medido por um cronômetro. Todos os sujeitos receberam o treino dos dois repertórios, porém em ordens distintas. Sessões de pré-teste e teste foram filmadas.

Condição concomitante, CC (sujeitos CC1 e CC2). Esta condição foi idêntica a condição do grupo experimental do estudo de Neves Filho et al. (2015). Os dois repertórios foram treinados em sessões intercaladas, no mesmo dia. As sessões ocorriam em sequência, uma imediatamente após a outra e a ordem das sessões variava a cada dia (por exemplo, um dia ocorreu o treino de cavar e depois o treino de escalar; em outro dia a ordem era invertida e assim por diante). O critério para encerrar o treino foi a obtenção de 15 cereais açucarados em duas sessões consecutivas. Caso o rato atingisse o critério para um dos repertórios em menos sessões que o outro, o procedimento continuaria da mesma forma até que os critérios para ambos repertórios fossem atingidos. O teste ocorreu logo após o animal ter atingido simultaneamente o critério de ambos repertórios.

Condição sucessiva, CS (sujeitos CS3 e CS4). Esta condição foi similar a uma das condições controle do estudo de Neves Filho et al. (2015). No estudo de Neves Filho et al., animais que aprenderam sucessivamente os dois repertórios tiveram a seguinte ordem exposição: (1) treino de cavar, (2) teste, (3) treino de escalar e (4) teste. No presente experimento, não foi realizado o teste entre o treino dos repertórios, de modo que a ordem de exposição dos sujeitos desta condição (CS) foi: (1) treino de cavar, (2) treino de escalar e (3) teste. Foram realizadas uma sessão por dia. Após atingir o critério de cavar (15 reforços em duas sessões consecutivas), o treino de cavar foi encerrado e deu-se início ao treino de escalar, também em uma sessão por dia. Após atingir o critério de aprendizagem de escalar (15 reforços em duas sessões consecutivas), foi realizado o teste.
Condição com retomada, CR (CR5 e CR6). A terceira condição foi idêntica a condição sucessiva (CS), com a adição de sessões de retomada. Assim como na condição sucessiva (CS), os animais aprenderam primeiro a cavar e depois a escalar. Após atingirem o critério no treino de escalar, foram realizadas sessões de retomada por três dias. As sessões de retomada consistiam em uma sessão de cavar, seguida de uma sessão de escalar, realizadas no mesmo dia, como feito na condição concomitante (CC). O teste foi realizado após o terceiro dia de sessões de retomada, independentemente do desempenho dos sujeitos nessas sessões.

\section{Resultados}

\section{Pré-teste}

Nenhum dos seis ratos resolveu a tarefa durante o pré-teste. Os comportamentos observados nesta sessão foram de erguer-se sobre duas patas, cheirar a divisória de acrílico, subir nas paredes laterais de arame e cavar em diferentes pontos da caixa, sem atravessar para o outro lado da caixa.

\section{Treino}

Dos seis ratos utilizados, cinco atingiram os critérios pré-estabelecidos de treino para passarem para a sessão de teste, de acordo com sua respectiva condição. O rato CR6 foi excluído do experimento, devido a problemas na obtenção de reforços, por causa de uma doença respiratória adquirida no decorrer da realização do experimento.

Os ratos da condição concomitante, CC1 e CC2 passaram por quatro sessões de treino de cada repertório até atingirem o critério de aprendizagem. Dos animais da condição sucessiva, CS3 precisou de quatro sessões para atingir o critério estabelecido para a tarefa de cavar, e outras seis sessões para o repertório de escalar, e CS4 precisou de cinco sessões para atingir o critério estabelecido para a tarefa de cavar e oito sessões para o repertório de escalar. O animal da condição de treino sucessiva com retomada (CR5) atingiu o critério em sete sessões de cavar e em 15 sessões de escalar, passando em seguida pelas três sessões de retomada previstas para esta condição (Tabela 1). 
Teste

Todos os ratos que atingiram os critérios de aprendizagem resolveram a tarefa final, recombinando os dois repertórios treinados, porém, com diferentes topografias de resolução (Tabela 1).

No teste, CC1 resolveu a tarefa pela primeira vez em 3 min $54 \mathrm{~s}$. CC1 iniciou a sessão explorando a caixa, aos 2 min $20 \mathrm{~s}$ começou a cavar próximo a barreira de acrílico e imediatamente encontrou a fresta e atravessou para o outro lado. Explorou e farejou as escadas, e aos 3 min $15 \mathrm{~s}$ atravessou a fresta de volta para o lado sem escadas, porém imediatamente retornou ao lado com escadas e escalou-as, resolvendo a tarefa aos 3 min $54 \mathrm{~s}$. Por ter retornado ao lado inicial da caixa, ao invés de atravessar e imediatamente subir as escadas, a topografia de solução de CC1 se encaixa na de tentativa-e-erro.

CC2 iniciou a sessão farejando a barreira acrílica e explorando a caixa. Cavou duas vezes ( $1 \mathrm{~min}$ 20 s e 2 min 49 s) em um dos cantos da caixa, afastado da barreira de acrílico. Aos 3 min $15 \mathrm{~s}$ cavou próximo a barreira de acrílico, encontrou a fresta e atravessou para o outro lado. Assim que atravessou, explorou e farejou o novo lado, até que começou a escalar as duas escadas aos 3 min $55 \mathrm{~s}$ e resolveu o problema aos $4 \mathrm{~min} 17 \mathrm{~s}$. Como CC2 subiu as escadas pouco depois de ter atravessado pela fresta, sua topografia se enquadra na topografia de "insight".
O rato CS3 cheirou o primeiro lado da caixa e a barreira, debruçando-se e empurrando a barreira com suas patas dianteiras até o minuto $1 \mathrm{~min} 32 \mathrm{~s}$, quando começou a cavar próximo a barreira. Parou e voltou a cavar duas vezes, até que aos 5 min $55 \mathrm{~s}$ encontrou a fresta e passou para o outro lado da caixa. Explorou este lado da caixa até começar a subir os patamares aos $8 \mathrm{~min} 28 \mathrm{~s}$ e pegar o cereal aos $8 \mathrm{~min} 40 \mathrm{~s}$. Como CS3 ficou vários minutos explorando o lado da câmara com as escadas, sem escalar imediatamente após cruzar para este lado, sua topografia de solução se assemelha a tentativa-e-erro.

$\mathrm{O}$ rato CS4 cheirou o primeiro lado da caixa e a barreira até os 4 min $50 \mathrm{~s}$, quando começou a cavar e passou para o outro lado aos $5 \mathrm{~min} 34 \mathrm{~s}$. No segundo lado da caixa explorou até $6 \mathrm{~min} 07 \mathrm{~s} \mathrm{e} \mathrm{co-}$ meçou a subir os patamares, obtendo o reforçador aos $6 \mathrm{~min} 20 \mathrm{~s}$. Como CS4 escalou pouco após ter cruzado a fresta na placa de acrílico, sua topografia de solução se enquadra na de "insight".

O rato CR5 passou para o segundo lado da caixa em 27 s, e explorou a maravalha. CR5 começou a subir as escadas no minuto $4 \mathrm{~min} 18 \mathrm{~s}$, obtendo o cereal em 5 min 12 s. Assim como CS3, CR5 permaneceu diversos minutos explorando o lado da câmara com as escadas, sem escalar imediatamente após cruzar para este lado, sua topografia de solução se assemelha a tentativa-e-erro.

\section{Tabela 1}

Resultados, e tempos de solução (min:s) para todos os sujeitos de todas as condições.

\begin{tabular}{|c|c|c|c|c|c|c|c|c|}
\hline Sujeito & $\begin{array}{l}\text { Solução no } \\
\text { pré-teste }\end{array}$ & $\begin{array}{l}\text { Sessões } \\
\text { de cavar }\end{array}$ & $\begin{array}{l}\text { Sessões } \\
\text { de escalar }\end{array}$ & $\begin{array}{l}\text { Emissão } \\
\text { do primeiro } \\
\text { repertório } \\
\text { (cavar) no } \\
\text { teste }\end{array}$ & $\begin{array}{l}\text { Emissão do } \\
\text { segundo } \\
\text { repertório } \\
\text { (escalar) no } \\
\text { teste }\end{array}$ & $\begin{array}{l}\text { Solução e tem- } \\
\text { po de solução } \\
\text { no teste }\end{array}$ & $\begin{array}{l}\text { Solução por } \\
\text { Insight }\end{array}$ & $\begin{array}{l}\text { Tempo entre } \\
\text { emissão } \\
\text { de cavar e } \\
\text { escalar }\end{array}$ \\
\hline $\mathrm{CC} 1$ & NÃO & 4 & 4 & $\begin{array}{l}\text { 02:02/ } \\
03: 15^{\star}\end{array}$ & 03:36 & SIM (3:54) & NÃO & $00: 21$ \\
\hline $\mathrm{CC} 2$ & NÃO & 4 & 4 & 03:15 & $03: 55$ & $\operatorname{SIM}(4: 17)$ & SIM & $00: 40$ \\
\hline CS3 & NÃO & 5 & 6 & 05:55 & $08: 28$ & SIM (8:40) & NÃO & $2: 33$ \\
\hline CS4 & NÃO & 6 & 8 & 05:30 & 06:07 & SIM $(6: 20)$ & SIM & $0: 37$ \\
\hline CR5 & NÃO & $7(+3)$ & $15(+3)$ & $00: 27$ & $04: 28$ & $\operatorname{SIM}(5: 12)$ & NÃO & 04:01 \\
\hline CR6 & NÃO & - & - & - & - & - & - & - \\
\hline
\end{tabular}

${ }^{\star} \mathrm{O}$ primeiro tempo indica quando o animal atravessou pela fresta da barreira de acrílico pela primeira vez. Como estes animais retornaram ao lado inicial da câmara experimental, o segundo tempo indica quando eles atravessaram a fresta pela segunda vez. 


\section{Discussão}

O objetivo principal desta pesquisa foi avaliar o efeito de repertórios treinados em ordens diferentes (concomitante ou sucessivo) sobre a recombinação de repertórios de ratos na tarefa de cavar e escalar. Os resultados indicaram que a ordem das sessões do treino dos repertórios de cavar e escalar, diferentemente do esperado, não determinou resolver ou não o problema, já que todos os animais, de todas as condições experimentais, resolveram a tarefa final. Os diferentes treinos também não controlaram consistentemente as topografias de solução observadas nos testes. Os ratos CC1, CS3, CR5 (um de cada condição experimental) não apresentaram uma topografia característica de "insight", ou seja, o comportamento apresentado por esses sujeitos durante o teste não foi súbito, direcionado e contínuo, na medida em que cruzaram a fresta, mas não escalaram imediatamente (CS3 e CR5), ou atravessaram a fresta repetidas vezes (CC1). Esta resolução com pausas indica que, apesar destes animais terem resolvido o problema, a ocorrência dos dois repertórios treinados não se deu pela recombinação dos mesmos, já que não foi observada uma sequência contínua de emissão das duas respostas (Epstein, 1996). Os demais ratos (CC2 e CS4) apresentaram a típica topografia de "insight" (uma resolução súbita, sem pausas entre a emissão das respostas que levam a solução do problema). Um resultado consistente com cada manipulação de treino foi o tempo requerido para resolver o problema, seja por tentativa-e-erro ou subitamente, na medida em que ratos da condição concomitante (CC1 e CC2) resolveram a tarefa em menor tempo que o rato CR5 (condição de retomada), enquanto que os ratos da condição sucessiva (CS3 e CS4) foram os que demoraram mais a resolver. $\mathrm{O}$ fato de que não houve um efeito diferencial, de acordo com o treino, sobre a topografia de "insight" pode ser discutido em dois termos, um metodológico e outro conceitual.

Metodologicamente, o presente estudo se distingue do estudo original de Neves Filho et al. (2015) por ter utilizado critérios de aprendizagem menos exigentes. Neves Filho et al. utilizaram um critério de 20 respostas corretas por quatro sessões consecutivas, enquanto que no presente experimento, o critério utilizado foi de 15 respostas corretas por duas sessões consecutivas somente.
Adicionalmente, no presente experimento ratos da condição sucessiva, que receberam um treino similar aos ratos dos grupos controle de Neves Filho et al. resolveram a tarefa, enquanto que dos quatro ratos do grupo controle de Neves Filho et al., que também receberam um treino sucessivo, somente um resolveu. Uma diferença metodológica que pode ser responsável por esse desempenho distinto, além dos diferentes critérios de aprendizagem, é a de que no procedimento de Neves Filho et al. ocorreu o treino do primeiro repertório, seguido de um teste, e depois o treino do outro repertório seguido de um segundo teste. No presente estudo, ocorreram os treinos sucessivos e um teste. É possível que o teste entre o treino sucessivo dos dois repertórios tenha tido um efeito deletério sobre a recombinação. Neste sentido, os dados ainda são inconclusivos quanto ao efeito de um treino sucessivo sobre a recombinação de repertórios na tarefa de cavar e escalar em ratos e o mesmo pode ser dito sobre estas manipulações de variáveis de treino na tarefa de deslocamento de caixa com ratos (Ferreira, 2008) e pombos (Neves Filho, 2015). Mais estudos controlando os critérios de aprendizagem e a apresentação da tarefa entre o treino dos repertórios pré-requisito precisam ser realizados para se avaliar qual o papel destas variáveis sobre a recombinação.

As diferentes topografias de solução ("insight" ou tentativa-e-erro) apresentadas pelos sujeitos, independentemente do tipo de treino dos repertórios pré-requisito, suscita também uma discussão conceitual em torno do "insight". Como já observado por Leonardi, Andery e Rossger (2011), a definição de "insight" ainda é insipiente e, neste sentido, a tentativa de analistas do comportamento de se manterem fiéis a definição inicial Köhler (1917/1948) pode ser contra produtiva. No caso do presente experimento, o treino independente dos repertórios pré-requisito levou todos os ratos a resolverem o problema. Estes mesmos ratos, sem o treino, não resolveram o problema. Portanto, pode-se afirmar que o treino foi o responsável pela resolução, que ocorreu de diferentes formas. A análise da forma, da topografia da resolução ("insight" ou tentativa-e-erro), assim como o tempo necessário para a mesma ocorrer, é um dado adicional, que não invalida o principal resultado: o treino independente produz a resolução do problema. Classificar como 
"insight" ou tentativa-e-erro, com base em critérios estritamente topográficos, talvez pouco acrescente ao dado.

Em resumo, como em Neves Filho et al. (2015), o procedimento de cavar e escalar mostrou-se uma alternativa para se observar e testar o efeito de variáveis de treino sobre a resolução de problemas em ratos. Manipulações de ordem de treino dos repertórios de cavar e escalar não controlaram consistentemente a topografia de solução do problema, o que pode ter sido resultado dos critérios de aprendizagem utilizados, ou mesmo de critérios de identificação do que é ou não uma topografia de "insight". Ao analisar diferentes topografias de resolução de um problema, a função é padronizada (comportamentos que levam a solucionar o problema), e a distinção se dá por critérios pouco padronizáveis, como por exemplo, o tempo entre emissão das respostas que levam a solução. Critérios topográficos como este são problemáticos quando aplicados entre indivíduos de espécies distintas. Ratos, por exemplo, se engajam em comportamentos de farejar enquanto se locomovem, enquanto que pombos não o fazem, o que resulta em uma diferença na forma como estes dois animais resolveriam um mesmo problema (ratos, consequentemente, levariam mais tempo, e emitiriam mais respostas exploratórias durante a resolução de um problema, em comparação com pombos). Os mesmos problemas de critério também são encontrados ao se comparar o desempenho de uma mesma espécie em duas tarefas distintas. Um dos ratos que resolveu a tarefa de deslocamento de caixa precisou de repetidas exposições ao teste para o fazer (Delage, 2006), enquanto que ratos na tarefa de cavar e escalar tendem a resolver na primeira exposição ao teste, dado o treino completo dos pré-requisitos (Neves Filho et al. 2015). Não há consenso na literatura se a resolução na primeira tentativa ou em tentativas subsequentes são diferentes tipos de topografia de "insight" (Neves Filho, 2015). Uma possível saída para este impasse seria observar e descrever a ocorrência de diferentes respostas fisiológicas nos diferentes tipos de topografia (cf. Kounios \& Beeman, 2014). Se diferentes topografias de resolução de um mesmo problema são acompanhadas de diferentes padrões de ativação cerebral, como parece ser o caso com humanos em problemas envolvendo anagramas (cf.
Jung-Beeman et al. 2004), seria então possível distinguir objetivamente quando uma solução é súbita ou não, evitando a arbitrariedade de critérios baseados somente na topografia.

De qualquer forma, a praticidade do equipamento (que pode ser facilmente montado) e a rapidez de aquisição dos repertórios (que requerem pouco mais de uma semana de treino) faz com que o procedimento de cavar e escalar seja econômico e de fácil aplicação, o que pode ser uma boa escolha tanto para projetos científicos interessados em melhor descrever e controlar as variáveis de treino que modulam a recombinação de repertórios, como também demonstrações didáticas deste processo comportamental, que ainda necessita de mais investigações acerca de variáveis de treino, assim como refinamentos em seus critérios.

\section{Referências}

Birch, H. G. (1945). The relation of previous experience to insightful problem-solving. Journal of Comparative Psychology, 38, 367-383. doi: 10.1037/h0056104

Carvalho Neto, M. B., Barbosa, J. I., Neves Filho, H. B., Delage, P. E. G. A. \& Borges, R. P. (2016). Behavior Analysis, creativity and insight. Em J. C. Todorov. (Ed.). Trends in behavior analysis: Volume 1. Brasília: Technopolitik Editora.

Cook, R. \& Fowler, C. (2014). "Insight" in pigeons: Absence of means-end processing in displacement tests. Animal Cognition, 17, 207-220. doi: 10.1007/s10071-013-0653-8

Delage, P. E. G. A. \& Galvão, O. F. (2010). Generalidade da aprendizagem em situações de uso de ferramentas por um macaco-prego, Cebus apella. Psicologia: Teoria e Pesquisa, 26, 687-694. doi: 10.1590/S010237722010000400012

Delage, P. E. G. A. (2006). Investigações sobre o papel da generalização funcional em uma situação de resolução de problemas ("insight") em Rattus norvegicus (Dissertação de Mestrado). Universidade Federal do Pará, Belém, Pará.

Delage, P. E. G. A. (2011). Transferência de aprendizagem no uso de ferramentas por MacacosPrego (Cebus cf apella) (Tese de Doutorado). Universidade Federal do Pará, Belém, Pará. 
Epstein, R. (1985). The spontaneous interconnection of three repertoires of behavior in a pigeon (Columba livia). Psychological Record, 35, 131141. doi: 10.1016/0149-7634(85)90009-0

Epstein, R. (1987). The spontaneous interconnection of four repertoires of behavior in a pigeon (Columba livia). Journal of Comparative Psychology, 101, 197-201. doi: 10.1037/07357036.101.2.197

Epstein, R. (1996). Cognition, creativity and behavior: Selected essays. Santa Barbara: Praeger.

Epstein, R., Kirshnit, C. E., Lanza, R. P. (1984). "Insight" in the pigeon: Antecedents and determinants of an intelligent performance. Nature, 308, 61-62. doi: 10.1038/308061a0

Ferreira, J. S. F. (2008). Comportamentos novos originados a partir da interconexão de repertórios previamente treinados: uma replicação de Epstein, Kirshnit, Lanza e Rubin, 1984 (Dissertação de Mestrado). Pontifícia Universidade Católica de São Paulo, São Paulo.

Hartmann, G. W. (1931). The concept and criteria of insight. Psychological Review, 38, 242-253. doi: $10.1037 / \mathrm{h} 0075595$

Hartmann, G. W. (1933). Insight vs. trial-and-error in the solution of problems. The American Journal of Psychology, 45, 663-677. Doi: $10.2307 / 1416194$

Holt, P. (2008). What is a problem? Theoretical conceptions and methodological approaches to the study of problem solving. European Journal of Behavior Analysis, 9, 157-172. doi: 10.1080/15021149.2008.11434302

Iversen, I. H. (2008). An inexpensive and automated method for presenting olfactory or tactile stimuli to rats in a two-choice discrimination task. Journal of the Experimental Analysis of Behavior, 90, 113-124. doi: 10.1901/ jeab.2008.90-113

Jung-Beeman, M., Bowden, E. M., Haberman, J., Frymiare, J. L., Arambel-Liu, S., Greenblatt, R., Reber, P. J., \& Kounios, J. (2004). Neural activity observed in people solving verbal problems with insight. PLOS Biology, 2, 500-510. doi: 10.1371/journal.pbio.0020097

Köhler, W. (1917/1948). The mentality of the apes (2nd ed.). New York: New Haven. (Originalmente publicado em 1917).
Köhler, W. (1959). Gestalt psychology today. American Psychologist, 14, 727-734. doi: 10.1037/h0042492

Kounios, J. \& Beeman, M. (2014). The cognitive neuroscience of insight. Annual Review of Psychology, 65, 71-93. doi: 10.1146/annurev-psych-010213-115154

Leonardi, J. L., Andery, M. A. P. A. \& Rossger, N. C. (2011). O estudo do insight pela análise do comportamento. Perspectivas em Análise do Comportamento, 2, 166-178.

Leonardi, J. L. (2012). "Insight": um estudo experimental com ratos (Dissertação de Mestrado). Pontifícia Universidade Católica de São Paulo, São Paulo.

Luciano, C. (1991). Problem solving behavior: an experimental example. Psicothema, 3, 297-317.

Maier, N. R. F. (1931). Reasoning and learning. Psychological Review, 38, 332-346. doi: 10.1037/ h0069991

Maier, N. R. F. (1937). Reasoning in rats and human beings. Psychological Review, 44, 365-378. doi: 10.1037/h0062900

Neves Filho, H. B. \& Carvalho Neto, M. B. (2013). A criatividade nas artes: A recombinação de repertórios comportamentais como processo básico. Boletim Contexto, 38, 133-145.

Neves Filho, H. B., Carvalho Neto, M. B., Barros, R. S., \& Costa, J. R. (2014). Insight em macacos-prego (Sapajus spp.) com diferentes contextos de treino das habilidades pré-requisitos. Interação em Psicologia, 18, 335-352. doi: 10.5380/psi.v18i3.31861

Neves Filho, H. B., Stella, L. R., Dicezare. R. H. F., Garcia-Mijares, M. (2015). Insight in the white rat: Spontaneous interconnection of two repertoires in Rattus norvegicus. European Journal of Behavior Analysis, 16, 188-201. doi:10.1080/15 021149.2015.1083283

Neves Filho, H. B., Carvalho Neto, M. B., Taytelbaum, G. P. M., Malheiros, R. S. \& Knaus, Y. C. (2016). Effects of different training histories upon manufacturing a tool to solve aproblem: Insight in capuchin monkeys (Sapajus spp.). Animal Cognition. doi: 10.1007/s10071-0161022-1

Neves Filho, H. B. (2015). Efeito de variáveis de treino e teste sobre a recombinação de repertórios em 
pombos (Columba Livia), ratos (Rattus norvegicus) e corvos da Nova Caledônia (Corvus moneduloides) (Tese de Doutorado). Universidade de São Paulo, São Paulo. Doi: 10.11606/T.47.2015. tde-15072015-101008

Pechstein, L.A. \& Brown, F. D. (1939). An experimental analysis of the alleged criteria of insight learning. Journal of Educational Psychology, 30, 38-52. doi: 10.1037/h0060872

Ruiz, G. \& Sánchez, N. (2014). Wolfgang Köhler's The Mentality of Apes and the animal psychology of his time. The Spanish Journal of Psychology, 28, e69. doi: 10.1017/sjp.2014.70

Schiller, P. H. (1952). Innate constituents of complex responses in primates. Psychological Review, 59, 177-191. doi: 10.1037/h0062854

Shettleworth, S. J. (2012). Do animals have insight, and what is insight anyway? Canadian Journal of Experimental Psychology, 66, 217-266. doi: 10.1037/a0030674

Slotnick, M. B. \& Schellinck, H. (2002). Behavioral methods on olfactory research with rodents. Em S. A. Simon \& M. Nicolelis (Eds.). Frontiers and methods in chemical senses. New York: CRC Press.

Sturz, B. R., Bodily, K. D. \& Katz J. S. (2009). Dissociation of past and present experience in problem solving using a virtual environment. CyberPsychology \& Behavior, 15, 15-19. doi: 10.1089/cpb.2008.0147

Taylor, A. H., Elliffe, D., Hunt, G. \& Gray R. D (2010). Complex cognition and behavioural innovation in new caledonian crows. Proceedings of the Royal Society B, 277, 26372643. doi:10.1098/rspb.2010.0285

Taylor, A. H., Knaebe, B. \& Gray, R. D. (2012). An end to insight? New Caledonian crows can spontaneously solve problems without planning their actions. Proceedings of the Royal Society B, 279, 4977-4982. doi: 10.1371/journal. pone. 0009345

Thorndike, E. L. (1911). Animal intelligence: Experimental studies. New York: The Macmillan Company.

Thorpe, W. H. (1963). Learning and instinct in animals. London: Methuen.
Tobias, G. K. S. (2006). É possível gerar "Insight" através do ensino dos pré-requisitos por contingências de reforçamento positivo em Rattus norvegicus? (Dissertação de Mestrado) Universidade Federal do Pará, Belém, Pará.

Tomasello, M. \& Call, J. (1997). Primate cognition. New York: Oxford University Press.

\section{Notas}

1. Após críticas (cf. Hartmann, 1931) e novas evidências empíricas (cf. Pechstein \& Brown, 1939; Birch, 1945; Schiller, 1952), Köhler (1959, p. 728) reformula o que seria o "insight" e a "reorganização perceptual", dando uma nova roupagem na qual o fenômeno seria a aprendizagem de relação entre eventos ou objetos, algo já esboçado na obra original (Köhler, 1917/1948, p. 228-229). Neste sentido, o "insight" na visão reformulada do autor é algo que se aproximaria do que hoje a psicologia comparada chama de "entendimento de causalidade" (Tomasello \& Call, 1997, p. 89). Colocar a interpretação de Köhler sobre a égide do mentalismo é fazer um espantalho da sua obra. A noção mentalista de "insight" como uma resolução mental, que ocorre antes da resolução do problema em si foi criada por terceiros (cf. Tomasello \& Call, 1997, p. 89; Taylor, Knaebe \& Gray, 2012). Para Köhler, a única coisa que antecede a resolução súbita é a compreensão, a aprendizagem, da "relação entre eventos", decorrente do contato ou observação da situação (Köhler, 1917/1948, p. 198). Nas palavras do autor “...devo advertir explicitamente meus leitores ao erro de pensar que eu estou deixando subentendido um modo sobrenatural de interpretar o comportamento" (Köhler, 1917/1948, p. 17, tradução livre).

\section{Informações do Artigo}

\section{Histórico do artigo:}

Submetido em: 16/03/2016

Primeira decisão editorial:

Aceito em: 16/08/2016

Editor Associado: Carlos Eduardo Costa 